\title{
Industrial Generation of Electricity in 1985: A Regional Forecast
}

\author{
Carlisle E. Moody, Jr.
}

\section{INTRODUCTION}

Industrial demand for electricity is a large fraction of the total demand facing electric utilities, accounting for 37 percent of all electricity consumption in $1975[8]$. This industrial demand is extremely important for utilities since it is a large and continuous demand and therefore can be satisfied with electricity produced by baseload plants. Baseload plants, usually coal or nuclear fueled, are the most fuel efficient plants available to utilities. Plants used to satisfy more variable demands, cycling and peakload plants, are less capital intensive but also less energy efficient. However, the industrial sector also has the most elastic demand for utility electricity due primarily to the ability of industrial firms to generate their own electricity. While only 7 percent of all electricity was self-generated in 1975 [7], rising electricity rates could result in a significant increase in this ratio and a corresponding loss of this important demand for utilities. Because of the high capital intensity of baseload electric plants, accurate forecasts of the level of industrial demand are necessary for efficient investment planning. Further, for public policy analysis, forecasts of the level of industrial demand are necessary to predict the mix of baseload, cycling and peakload plants required to meet a given electricity demand, especially since there has been much interest recently in electricity rate reform [1].

While several studies have estimated the industrial demand for electricity [see, e.g. 4], this paper explicitly estimates the relationship between the industrial self-generation of electricity and electricity prices, an area of analysis which to our knowledge has not been explicitly modelled. The result is a possibly sharper analysis of the industrial demand for electricity, given the choice to self-generate, and perhaps more accurate forecasts of energy demand. Further, this study recognizes the regional differences that characterize energy systems, including utility electric systems. We use this regional model to forecast industrial generation of electricity in 1985 under the Department of Energy Reference Scenario and under an electricity rate reform scenario which would implement marginal cost prices for electricity. 


\section{THE REGRESSION MODEL}

The choice of a manufacturing firm to purchase electricity or produce it internally is a cost-benefit decision regarding a particular form of vertical integration. The benefit is the reduction in costs for purchased electricity while the corresponding cost is the required purchase of capital, labor and materials necessary to self-generate the electricity. In equilibrium the marginal benefit (the real price of electricity) will equal the marginal cost of generating electricity. The marginal cost of generating electricity is a function of the real prices of the fuels used as well as the real prices of the required capital and labor:

$$
\mathrm{E}_{\mathrm{ijk}}=\mathrm{E}_{\mathrm{ijk}}\left(\mathrm{P}_{\mathrm{D}}, \mathrm{P}_{\mathrm{R}}, \mathrm{P}_{\mathrm{G}}, \mathrm{P}_{\mathrm{E}}\right)
$$

where $E_{i j k}$ is electricity generated by firm $k$ in region $j$ in industry $i$ and $P_{D}$ is the price of distillate fuel oil, $P_{R}$ is the price of residual fuel oil, $P_{G}$ is the price of natural gas, and $\mathrm{P}_{\mathrm{E}}$ is the price of electricity.

Aggregating across firms requires the addition of a variable measuring the level of industrial activity since large firms will find it more efficient to self-generate than smaller firms:

$$
E_{i j}=E_{i j}\left(P_{D}, P_{R}, P_{G}, P_{E}, Q\right)
$$

where $Q$ is the value added by manufacture in region $j$ and industry $i$. Finally, aggregating across industries requires the addition of a variable measuring the industrial composition of the region since certain industries (specifically paper, chemicals and oil refining) generate large amounts of process steam which can be readily converted into electricity:

$$
E_{i}=E_{i}\left(P_{D}, P_{R}, P_{G}, P_{E}, Q, P C T\right)
$$

where PCT is the proportion of value added by manufacture in region $\mathrm{i}$ from paper (SIC26), chemicals (SIC28) and petroleum and related products (SIC29). We ignore the wage rate of the additional labor necessary to generate the electricity since it is a small proportion of the cost. We also exclude the annualized cost of the required capital equipment since it will not vary by region.

We are left with the hypothesis that the level of self generation of electricity in a region is negatively related to the prices of the fuels used to generate electricity and positively related to the price of electricity, the level of manufacturing activity, and the relative importance of the paper, chemical and petroleum industries. A reasonable preliminary specification of this hypothesis is the following (in natural logarithms):

$$
\begin{aligned}
& \ln (\mathrm{G} / \mathrm{E})=\alpha_{0}+\alpha_{1} \ln \mathrm{PD}+\alpha_{2} \ln \mathrm{PR}+\alpha_{3} \ln \mathrm{PG}+\alpha_{4} \ln \mathrm{PE}+ \\
& \alpha_{5} \ln \mathrm{VAM}+\alpha_{6} \ln \mathrm{PCT} \\
& \text { where }
\end{aligned}
$$

$\mathrm{G}$ is industrial electricity generated, less sold, 
$\mathrm{E}$ is purchased electricity,

PD is average price of distillate fuel oil,

$P R$ is average price of residual fuel oil,

$\mathrm{PG}$ is average price of natural gas,

$\mathrm{VAM}$ is value added by manufacture

PCT is the percentage of VAM due to industries 26, 28 and 29.

The observations are by state from the 1972 Census of Manufactures [6]. ${ }^{1}$ Data on net generation of electricity would be preferable to electricity generated less sold. However, this is the only data available from the Census of Manufactures. The purpose of this preliminary regression is to identify the significant variables for a prediction equation based on better and more recent data, while avoiding some pre-testing bias. In the absence of an appropriate regional price deflator, all prices are assumed to be proportional to real prices.

The preliminary regression results are reported in Table 1 . The only variables which are significant determinants of the ratio of electricity generated less sold to purchased electricity are the price of electricity and the percentage of VAM due to paper, chemicals, and petroleum. Value added by manufacture is not significant presumably because any scale effects have been wiped out by the choice of $G / E$ rather than $G$ as the dependent variable. ${ }^{2}$ It is interesting that none of the alternative fuel price variables is significant in the regression. However, this is not completely unexpected for two reasons. First, these fuels are also used by electric utilities to generate electricity. Therefore regions which have high fuel prices will also tend to have high electricity prices. Also, a competitive energy market will equalize energy prices per BTU across fuels, adjusted for other characteristics of the fuels. Thus distillate fuel oil will always have a higher price per gallon than residual fuel oil because it is a more desirable

TABLE 1

\section{PRELIMINARY DEMAND EQUATION FOR SELF-GENERATED ELECTRICITY}

Dependent Variable: $\ln (\mathrm{G} / \mathrm{E})$

$\begin{array}{lcc}\text { Independent Variables } & \text { Coefficient } & \text { T-Score } \\ \operatorname{lnPD} & 0.58 & 0.44 \\ \ln P R & -0.62 & 0.47 \\ \operatorname{lnPG} & -0.75 & 1.52 \\ \operatorname{lnPE} & 1.42 & 2.75 \\ \operatorname{lnVAM} & -0.16 & 1.35 \\ \operatorname{lnPCT} & 1.09 & 4.22 \\ \text { Intercept } & 7.69 & 0.92 \\ \mathrm{RSQ}=.57 & \mathrm{RSQBAR}=.48 & \\ \mathrm{~F}=5.69 & \mathrm{~N}=32 & \end{array}$


fuel but an exogenous increase in the price of distillate fuel will cause the price of residual fuel to increase to restore BTU equilibrium. Similarly, an exogenous increase in the price of natural gas (or coal or imported crude oil) will cause all other energy prices to increase (including the price of electricity). For these reasons it is unnecessary to include all fuel prices in the prediction equation for industrial self-generation since their influence will be captured by the price of electricity. The decision to generate electricity by industrial firms in a region will therefore be determined primarily by available technology and the real price of electricity in that region. In this analysis the available technology is captured by the industrial composition variable (PCT) which measures the relative importance of large process steam producers in each region.

With these preliminary results analyzed we turn to the collection of better and more recent data. Using the Annual Surveys of Manufactures [5] we collect data on purchased electricity $(\mathrm{E})$, value added by manufacturing (VAM) and value added by industries 26,28 and 29 by state for the years 1975 and 1976. In addition we collect data on net generation of electricity by industrial establishments (GEN) for the same states and years from the Federal Energy Regulatory Commission [7]. The price of electricity is deflated by the Producer's Price Index for all commodities.

In order to use these data most effectively, the samples were pooled to form a single sample of two cross sections. With more than one observation on each state we can do a more detailed study by allowing each state and year to have its own intercept while estimating the coefficients on the price of electricity and the industrial composition. The regression technique is least squares dummy variables (LSDV) which has several desirable econometric properties $[2,3]$ not the least of which is that by including a dummy variable for each state we allow for omitted state-specific characteristics which could affect the amount of industrial generation in each state. ${ }^{3}$ We are therefore capable of doing an explicitly regional analysis for eventual use in forecasting regional industrial generation levels. We therefore propose the following model

$$
\ln (\mathrm{GEN} / \mathrm{E})_{\mathrm{it}}=\alpha+\beta_{1976}+\sum_{\mathrm{i}=2}^{50} \mathrm{Y}_{\mathrm{i}}+\delta_{1} \operatorname{lnPE}_{\mathrm{it}}+\delta_{2} \operatorname{lnPCT} \mathrm{it}+\epsilon_{\mathrm{it}}
$$

where $t$ refers to the two years 1975 and 1976 and $i=1, \ldots, 50$ is the index for states. To avoid the dummy variable trap we exclude one state dummy (Maine) and one year dummy (1975) and include an overall intercept, $\alpha$. This means that $\beta$, the coefficient on the 1976 dummy variable and $Y_{i}$, the coefficient on the dummy variable for state i will estimate the difference between these intercepts and the overall intercept for Maine in 1975. This procedure allows us, in effect, to estimate a forecasting equation for each state where the coefficients on the continuous variables $\left(\delta_{1}\right.$ and $\left.\delta_{2}\right)$ are restricted to be equal across regions. However, one Monte Carlo study has shown that LSDV is even a good method of estimating a random coefficients model where the coefficients on the continuous variables are allowed to vary across regions [2]. The results of the LSDV regression are presented in Table 2. 
TABLE 2

\begin{tabular}{|c|c|c|c|c|c|}
\hline \multicolumn{6}{|c|}{ Dependent Variable: $\ln ($ GEN/E) } \\
\hline Var. & Coeff. & T score & Var. & Coeff. & T score \\
\hline $\ln P E$ & .818 & 2.25 & ALA & -2.014 & -18 \\
\hline $\ln \mathrm{PCT}$ & .189 & 1.61 & ARK & -1.279 & -11.83 \\
\hline$\alpha$ & 4.129 & 2.33 & LA & -0.305 & -1.47 \\
\hline$\beta 1976$ & -0.089 & -3.66 & $\mathrm{TX}$ & -0.937 & -6.06 \\
\hline $\mathrm{NH}$ & -1.597 & - 9.03 & COL & -2.247 & -12.58 \\
\hline VT & -2.224 & -14.02 & $\mathrm{ARZ}$ & -0.740 & -3.89 \\
\hline MA & -2.537 & -11.47 & WASH & -2.744 & -5.35 \\
\hline RI & -4.521 & -10.63 & OR & -2.554 & -7.28 \\
\hline C.T & -3.211 & -15.11 & CAL & -2.97 & -22.07 \\
\hline MY & -2.414 & -18 & $\mathrm{NJ}$ & -3.374 & -17.36 \\
\hline $\mathrm{PA}$ & -2.181 & -15.86 & DEL & -2.64 & -16.06 \\
\hline $\mathrm{OH}$ & -2.642 & -20.28 & ND & 0.065 & 0.08 \\
\hline IND & -1.157 & -8.51 & NEB & -6.838 & -50.3 \\
\hline ILL & -2.798 & -22.76 & MISS & -2.142 & -19.25 \\
\hline $\mathrm{MICH}$ & -1.874 & -11.26 & $\mathrm{OK}$ & -3.305 & -20.77 \\
\hline WIS & -1.808 & -13.78 & MON & -4.94 & -9.22 \\
\hline MIN & -0.721 & -5.76 & IDA & -2.752 & -9.22 \\
\hline ID & -2.476 & -17.77 & WYD & 0.089 & 0.60 \\
\hline MO & -2.918 & -25.19 & NM & -0.144 & -1.08 \\
\hline SD & -0.958 & -1.20 & UTAH & 0.356 & 2.00 \\
\hline $\mathrm{KA}$ & -3.641 & -32.63 & NEV & -1.76 & -10.67 \\
\hline MD & -1.908 & -14.17 & ALSK & 1.915 & 2.41 \\
\hline $\mathrm{VA}$ & -1.551 & -12.12 & $\mathrm{HI}$ & 1.593 & 1.91 \\
\hline WVA & -1.392 & -11.08 & & & \\
\hline NC: & -2.703 & -22.82 & & & \\
\hline SC: & -2.029 & -18.76 & & & \\
\hline G;A & -1.682 & -13.16 & & & \\
\hline FL & -1.565 & -9.97 & & & \\
\hline KY & -6.638 & -39.2 & & & \\
\hline TN & -2.938 & -21.92 & & & \\
\hline $\mathrm{R}^{2}=.9979$ & & $\overline{\mathrm{R}}^{2}=.9956$ & & $F=433.8$ & \\
\hline
\end{tabular}

Examination of Table 2 reveals that we have explained virtually all the variation of the dependent variable $(\mathrm{RSQ}=.998)$ and almost all the state coefficients are significantly different from zero at the customary significance levels indicating that there are significant differences among states with respect to the importance of industrially generated electricity even after allowing for differences in the price of electricity and the industrial composition in the state. This verifies the often stated hypothesis that factors influencing industrial generation of electricity are site specific and not easily generalized across regions. With respect to the price of electricity, its coefficient is 0.818 with a t-score of 2.25 . Thus a one percent increase in the price of electricity is estimated to cause a .8 percent increase in the ratio of self-generated to purchased electricity. This is a relatively powerful result which could imply serious consequences for electric utilities in times of increasing fuel cost costs. The coefficient on electricity 
price is smaller here than in the preliminary 1972 regression presumably because of the necessary omission in that regression of the individual state and time effects which are captured by the state and year dummy variables in the LSDV regression. Similarly the industrial composition variable, PCT, is no longer significant since much of its influence is captured by the state dummies. The 1976 year dummy variable is highly significant and negative, indicating a downward shift from 1975 to 1976 in the ratio of self-generated to purchased electricity, holding the price of electricity, industrial composition, and other regional specific influences constant. This result is as expected given that the total amount of industrial generation has been declining steadily since 1972 [7].

\section{INDUSTRIAL GENERATION OF ELECTRICITY IN 1985: BASE CASE}

In this section we use the estimated equation (5) reported in Table 2 to forecast the ratio of generated to purchased electricity by state in 1985 on the basis of the Department of Energy Reference Forecast. We also forecast the total amount of industrial generation in 1985 by region under the same reference forecast.

In order to forecast industrial generation in 1985 we need to consider three variables: the proportion of value added by manufacturing due to industries 26, 28 and 29, the real price of electricity in 1985, and the time trend. Since we have no information on projected industrial mix by state in 1985, we assume PCT will retain its 1975-1976 average value. The forecast real price of electricity to industrial users in 1985 is taken from the Department of Energy 1985 Reference Forecast [8]. This forecast is made on a regional level rather than by state, so we assume that the DOE regional price is constant across all states within a region. The coefficient on the time dummy variable in the LSDV regression is highly significant, indicating a downward shift in the ratio of generated to purchased electricity on the part of industrial consumers. Since this is consistent with Survey of Manufactures [5] data showing a continuous decline in the total amount of industrial generation, we expect this strong negative trend to continue to 1985.

The forecast value of the ratio of generated to purchased electricity in 1985 for the base case is presented in Table 3, column 2, with the corresponding values for 1976 presented in column 1 for comparison. Comparing columns one and two, we can see that the strong negative trend more than offsets the effect of rising real electricity prices for most states. The states of Indiana, Missouri, South Dakota, Nebraska, Oklahoma, Montana, New Mexico, Nevada, Alaska and Hawaii show increases in generated to purchased industrial electricity and most of these states are relatively insignificant with respect to either total industrial energy use or the actual change in the ratio. The important exceptions are Louisiana and Texas which are large energy users and where a small change in the ratio of generated to purchased electricity could have a significant effect on the electric and energy systems in that region. 
TABLE 3

RATIO OF GENERATED TO PURCHASED ELECTRICITY 1985

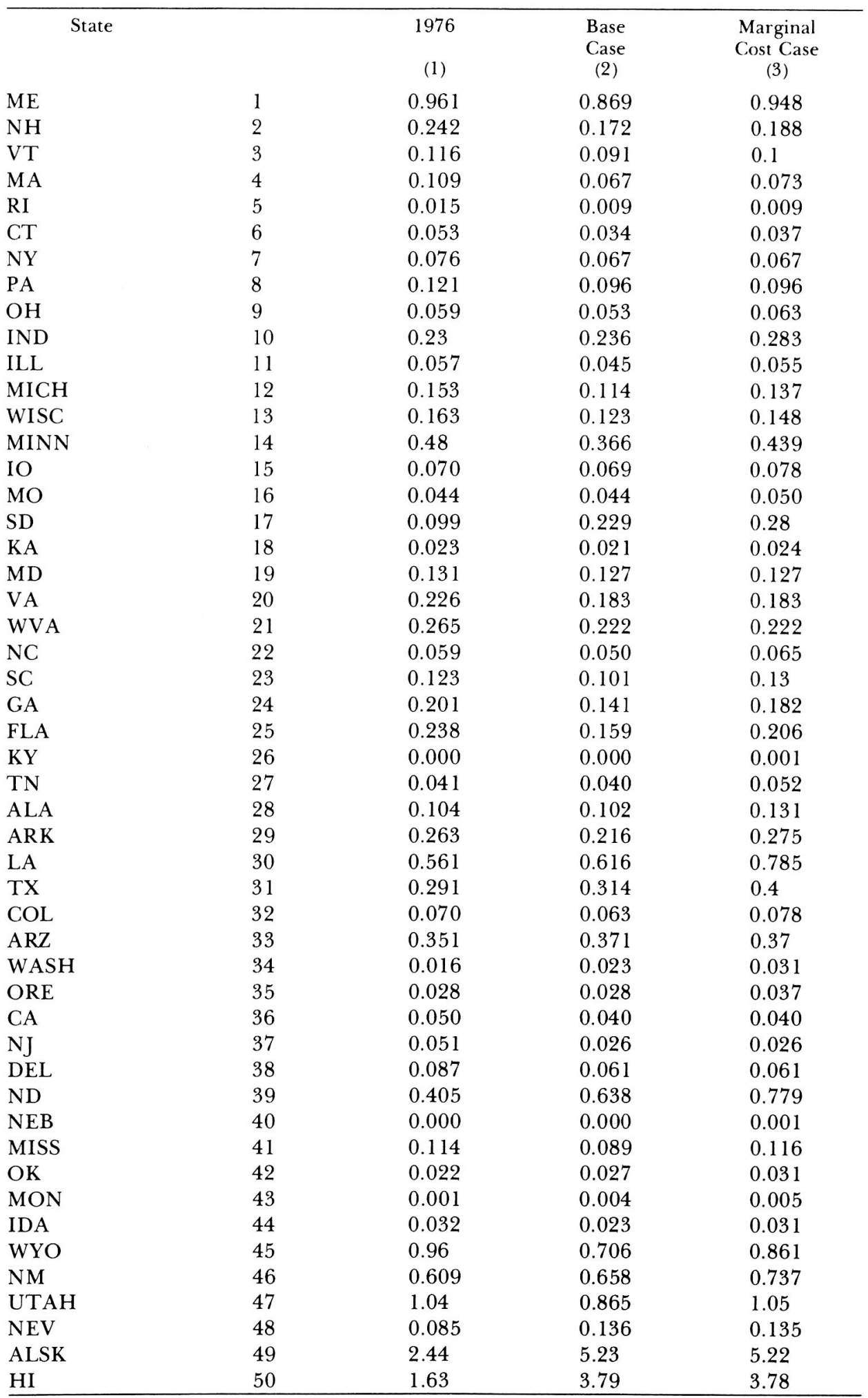


In order to predict total industrial generation in 1985 , we need a forecast of purchased electricity to which we can apply the ratios in Table 3. The Department of Energy Reference case was again used for this purpose. As before, the DOE forecasts only on the basis of ten energy demand regions. Thus, we applied the average GEN/ELQ ratio for states in each region, weighted by purchased electricity in 1976, to the DOE forecast for purchased electricity in 1985. The results are reported in Table 4. According to our baseline forecast, industrial generation will amount to 157 billion kilowatt-hours in 1985 with the largest proportion being produced in the Midwest and Southwest regions (which together are forecast to account for 58 percent of all industrial generation).

This result is interesting in that while the ratio of generated to purchased electricity is forecast to decline in the base case for most states, the level of industrial generation is forecast to increase substantially. Thus, the rise in industrial electricity prices which is expected over the next several years is forecast to reverse the downward trend in industrial generation.

TABLE 4

ELECTRICITY GENERATED BY INDUSTRY
1985
(millions of kilowatt - hours)

\begin{tabular}{|c|c|c|c|c|c|}
\hline \multicolumn{2}{|r|}{ Region* } & $\begin{array}{c}\text { Base } \\
\text { Case } \\
(1)\end{array}$ & $\begin{array}{c}\text { Marginal } \\
\text { Cost Case } \\
\text { (2) }\end{array}$ & $\begin{array}{l}\text { Difference } \\
\text { (3) }\end{array}$ & $\begin{array}{l}\text { Percen } \\
\quad(4)\end{array}$ \\
\hline & NE & 5615 & 6065 & 450 & 8.01 \\
\hline 2 & $\mathrm{NY} / \mathrm{NJ}$ & 3960 & 4046 & 86 & 2.17 \\
\hline 3 & MA & 17400 & 17816 & 416 & 2.39 \\
\hline 4 & SA & 19928 & 23760 & 3832 & 19.23 \\
\hline & MW & 31506 & 35800 & 4294 & 13.63 \\
\hline 6 & SW & 59670 & 73555 & 13885 & 23.27 \\
\hline & CEN & 2316 & 2540 & 224 & 9.67 \\
\hline & N. CEN & 6288 & 7082 & 794 & 12.63 \\
\hline & WEST & 7576 & 7714 & 138 & 1.82 \\
\hline 10 & NW & 3163 & 3394 & 231 & 7.30 \\
\hline & U.S. & 157422 & 181772 & 24350 & 15.47 \\
\hline
\end{tabular}

*The FEA regions are defined as follows:

1 NE: ME, NH, VT, MA, CT, RI

$2 \mathrm{NY} / \mathrm{NJ}: \mathrm{NY}, \mathrm{NJ}$.

3 MA: PA, DEL, MD, VA, WVA.

4 SA: NC, SC, GA, FL, KY, TN, MISS, AL.

5 MW: OH, IND, MICH, IL, WISC, MINN.

6 SW: ARK, LA, TX, OK, NM.

7 CEN: IO, MO, NEB, KA.

8 N. CEN: ND, SD, MON, WYO, UT, COL.

9 WEST: NEV, ARZ, CAL, HI

10 NW: WASH, ORE, ID, AK 
(In 1972 industrial generation was 104.5 billion $\mathrm{kwh}$; by 1977 it had fallen to 87.0 billion $\mathrm{kwh}[7]$.)

\section{INDUSTRIAL GENERATION IN 1985 UNDER ELECTRICITY RATE REFORM}

Included in the proposed National Energy Plan is an electricity rate reform program which could have a significant impact on the level of industrial generation. While there is much disagreement as to the final form that rate reform will take, if passed, we chose to analyze the most dramatic case-namely, marginal cost or replacement cost pricing of electricity. Under this scheme electricity consumers will have to pay a price of electricity determined by cost of the last kilowatt-hour generated. In a period of rising fuel and capital costs, this means that the price of electricity will be substantially higher than the price which would have been charged under current regulatory practice, which is a price based on the average cost rather than the marginal cost of production. Results of a run of DOE's PIES model to simulate such a regulatory change are reported in $[1]$. It was assumed for the purposes of this run that the reform improved the load factor for utilities from the current average of 60 percent to a 1985 average of 65 percent nation-wide. The improvement in load factor occurs because marginal cost pricing includes peak load pricing since the cost of generating for peak demand is higher than the cost of generating for baseload demand. The net effect is an average 20 percent rise in the price of electricity to industry, a rise which would have been even higher had the load factor not improved.

We use the PIES forecast regional industrial price of electricity and our equation (2) to predict the ratio of generated to purchased electricity by state in 1985. Again we assumed that the regional price is constant across all states in that region. The results are reported in Table 3, column 3. Comparing the base case to the marginal cost case, we see that the ratio of generated to purchased electricity increased in most states although eleven showed no change or even a tiny decline. ${ }^{4}$ However, it is also true that we find the downward trend of GEN/ELQ in many states is forecast to be reversed under marginal cost pricing of electricity. For seventeen states the ratio of generated to purchased electricity will be higher under this rate reform than it was in $1976 .^{5}$

The corresponding level of generation implied by these electricity prices and the implied demand for industrial purchased electricity under rate reform is presented in Table 4 , column 2. Examination of Table 4 reveals that forecast industrial generation will increase in all regions with the largest increases occurring in the South Atlantic and Southwest (La. and Texas). Overall, we expect a 15 percent increase in industrial generation under marginal cost pricing of electricity. This represents a substantial decline in the industrial demand for utilities and, since this demand is steady baseload demand, the expected increase in load factors under rate reform may be overstated. 


\section{SUMMARY AND CONCLUSIONS}

We have derived a regression equation based on recent time series and cross section data which tests the hypothesis that industrial generation is responsive to electricity prices and the industrial output mix. We found that in fact the ratio of generation to purchased electricity, hence the level of generation, is sensitive to price but it also varies widely across regions and has been declining over time. With this regression model we forecast the ratio of generation to purchased electricity by state for 1985 using the PIES reference forecast of electricity prices. We found that while some states showed small increases in the ratio of generated to purchased electricity, the expected rise in electricity prices failed to reverse the downward trend in GEN/ELQ for most states. The exception occurs in Texas and Louisiana where GEN/ELQ is forecast to go up by 1985 . We used the corresponding PIES reference forecast of industrial purchased electricity to predict the level of generation by region in 1985 . The forecast rise in electricity prices was found to predict an increase in the level of industrial generation, a reversal of the strong downward trend observed in the period 1972-1976.

We also analyzed an electric rate reform case based on marginal cost pricing of electricity. Under this scenario the ratio of generated to purchased electricity increases over the base case and even reverses the downward trend in several states. The PIES model was used to generate the industrial prices and purchase electricity amounts for this case. We find that the level of industrial generation increases by a factor of 15 percent over the base case with the largest increases coming in the South Atlantic and Southwest PIES regions. As a result we caution that the expected increase in utility load factors under rate reform proposals like the marginal cost reform analyzed here are likely to be overestimated unless some consideration is taken of increased industrial generation.

\section{FOOTNOTES}

'Only 32 states had data on all relevant variables: these states are Maine, New Hampshire, Vermont, Massachusetts, Pennsylvania, Ohio, Indiana, Illinois, Michigan, Wisconsin, Minnesota, Iowa, Maryland, West Virginia, North Carolina, South Carolina, Georgia, Florida, Tennessee, Alabama, Mississippi, Arkansas, Louisiana, Texas, Oklahoma, Colorado, Árizona, Nevada, Washington, Oregon, California and Alaska.

'The choice of $G / E$ rather than $G$ was dictated by the following considerations. Firms engaged in self generation also tend to be large purchasers of electricity. Given the declining block structure of electricity prices, this implies that the average price of electricity is relatively low to these firms. This results in a positive correlation between $G$ and $E$ and a negative correlation between $E$ and $\mathrm{PE}$ which would cause an incorrect negative coefficient on the price of electricity. Regressing G/E on PE yields the correct sign but renders the VAM variable insignificant.

${ }^{3}$ Justification for the use of LSDV over other pooling techniques can be found in [2,3].

Specifically: PA, MD, VA, WVA, ARZ, CAL, NJ, DEL, NEV, ALSK, AND HI.

${ }^{5}$ These states are: ID, MD, SD, KA, NC, SC, KY, TN, ALA, ARK, LA, TX, COLO, ARZ, WASH, ORE, ND, NEB, MISS, OK, MON, IDA, NM, UTAH, NEV, ALSK, AND HI.

\section{REFERENCES}

1. Hogarty, T., W. Kruvant, and C. Moody. "An Analysis of Some Peak Load Pricing SchemesSimulations to 1990." Paper presented to the Atlantic Economic Society, October, 1978.

2. Johnson, K. H. and H. L. Lyon. "Experimental Evidence on Combining Cross-Section and Time Series
Information." Review of Economics and Statistics 55 (November, 1973), pp. 465-474.

3. Mundlak, Y. "On the Pooling Time Series and Cross Section Data." Econometrica 46 (January, 1978), pp. 69-86.

4. Taylor, L. D. "The Demand for Electricity: A Sur- 
vey." Bell Journal of Economics 6 (Spring, 1975), pp. 74-110.

5. U.S. Bureau of the Census. Annual Survey of Manufactures. Washington, D.C.: U.S. Government Printing Office, various issues.

6. 1972 Census of Manufactures. Washington, D.C.: U.S. Government Printing Office, 1972.
7. U.S. Department of Energy. "EIA Issues Power Production, Generating Capacity Data for 1972 to 1977." Energy Data Reports. DOE/EIA-0052/1 (June, 1978).

8. "1985 Mid-Range/Trendlong Scenario with Natural Gas Regulation." PIES Model Run, March $16,1978$. 